\title{
Multi-Gigabit Capacity W-band Hybrid Wireless-Photonic Transmission Link
}

\author{
Vegas Olmos, Juan José; Pang, Xiaodan; Lebedev, Alexander; Tafur Monroy, Idelfonso
}

Published in:

Proceedings of Asia Communications and Photonics Conference,

Publication date:

2013

Document Version

Publisher's PDF, also known as Version of record

Link back to DTU Orbit

Citation (APA):

Vegas Olmos, J. J., Pang, X., Lebedev, A., \& Tafur Monroy, I. (2013). Multi-Gigabit Capacity W-band Hybrid Wireless-Photonic Transmission Link. In Proceedings of Asia Communications and Photonics Conference, [ATh3G.1] Optical Society of America.

\section{General rights}

Copyright and moral rights for the publications made accessible in the public portal are retained by the authors and/or other copyright owners and it is a condition of accessing publications that users recognise and abide by the legal requirements associated with these rights.

- Users may download and print one copy of any publication from the public portal for the purpose of private study or research.

- You may not further distribute the material or use it for any profit-making activity or commercial gain

- You may freely distribute the URL identifying the publication in the public portal

If you believe that this document breaches copyright please contact us providing details, and we will remove access to the work immediately and investigate your claim 


\title{
Multi-Gigabit Capacity W-band Hybrid Wireless-Photonic Transmission Link
}

\author{
J.J. Vegas Olmos, X. Pang, A. Lebedev, and I. Tafur Monroy \\ Department of Photonics Engineering, Technical University of Denmark, Ørsted Plads 343, Kgs. Lyngby, 2800, Denmark \\ jjvo@fotonik.dtu.dk
}

\begin{abstract}
We present a 10-meter bidirectional fiber-wireless-fiber system at $81 / 86-\mathrm{GHz}$ (Wband). The fiber transmission amounts for $36-\mathrm{km}$, whereas the wireless transmission for $10-\mathrm{m}$, achieving BER performance below the 7\% FEC limit for both downstream and upstream. OCIS codes: (060.4510) Optical Communications; (060.5625) Radio frequency photonics; (250.0250) Optoelectronics.
\end{abstract}

\section{Introduction}

Hybrid photonic-wireless systems are envisaged to seamlessly provide high-capacity connections over multiple scenarios, such as information beacons for mobile users (high capacity access in a single public spot) and wireless bridges to overcome last mile physical or economic obstacles to reach further optical distribution networks. Radioover-fiber (RoF) techniques are supporting to bridge the gap between the large capacity of optical fibers and the flexibility of wireless transmission [1][2]. RoF research is now focusing on enabling hybrid photonic-wireless links at high frequency bands and increasing the channel capacity. Therefore, there is a global effort to develop novel technologies to exploit the $60 \mathrm{GHz}[3][4][5], 75-110 \mathrm{GHz}$ [6][7][8][9] and even sub-THz [10] bands. Our current work is centralized on the W-band $(75-110 \mathrm{GHz})$, which is attractive because of its wide frequency bands, and seems to be an accepted good choice for transmission capacities in the order of multi-gigabits. This capacity increase is yield through the usage of advanced modulation formats instead of traditional on-off keying (OOK). Figure 1 shows some of the networks scenarios that directly benefit of large capacity hybrid W-band photonicwireless links: the generation of W-band signals can be done centralized and then distribution is done via passive or active optical networks to feed systems such as information beacons or to bridge last mile obstacles. In both cases, it is clear that the wireless link needs to be able to range from few meters to, in some cases, hundreds.

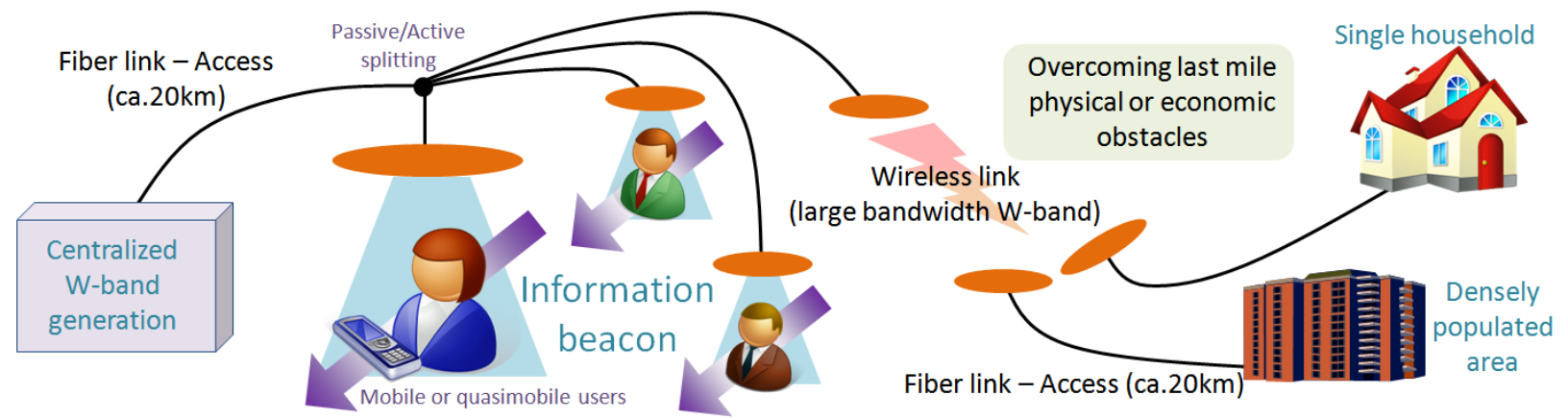

Fig. 1. Network scenarios for a hybrid fiber-wireless and a fiber-wireless-fiber link.

A main limitation of RoF systems is the poor conversion efficiency of the opto-electro-opto processes; namely, the efficiency of photodiodes and modulators. This efficiency shortcoming, in practical terms, introduces a limitation in the wireless range achieved by most experimental demonstrations of RoF systems, sometimes in the order of few centimeters or meters. This limitation may not affect scenarios such as short distance communications in data centers or indoor distributed antenna systems. However, scenarios such as shown in Fig. 1, require transmission distances in the order of tens of meters. In this paper, we show an active transmitter enabling wireless transmission up to 10 meters. The overall system consists of a bidirectional hybrid photonic-wireless link, comprising a fiber link, a wireless bridge, and a final fiber link.

\section{Experimental demonstration}

Figure 2 presents the experimental setup of the proposed bidirectional wireless hybrid fiber-wireless link. At the downlink (DL) transmitter, a continuous-wave (CW) lightwave at $1550.2 \mathrm{~nm}$ from an external cavity laser (ECL 1) is fed into a Mach-Zehnder modulator (MZM), which is driven by a $20.35 \mathrm{GHz}$ modulation signal; adjusting the 
applied bias voltage to the modulator, second order harmonics of the driving signal can be generated at the modulator output [11]. The signal from the MZM goes to an arrayed waveguide grating (AWG) with $50 \mathrm{GHz}$ channel grids, which is used to block the optical central carrier while separating the upper / lower sidebands (USB / LSB). The frequency separation between the USB and LSB is $81.4 \mathrm{GHz}$. The LSB is modulated by an integrated $\mathrm{LiNbO}_{3}$ dual-parallel MZM driven by a two-channel 8 Gbaud pseudo-random binary sequences (PRBS) with a word length of $2^{15}-1$, resulting in a $16 \mathrm{Gbit} / \mathrm{s}$ QPSK signal at the output. Simultaneously, the USB is polarization aligned and combined with the LSB using a 3-dB coupler, acting as a carrier generating local oscillator (LO) later for the optical heterodyne up-conversion. The optical spectra of the AWG channels and the combined signal are shown in Fig. 2 (a). At the output of the DL transmitter, the combined signal and LO forming a single side-band (SSB) RoF signal is launched into a $26 \mathrm{~km}$ standard single mode fiber (SSMF). After transmission, the signal is up-converted to a W-band RF signal at a $100 \mathrm{GHz}$ photodetector (PD 1), subsequently amplified by a W-band power amplifier and then radiated. The wireless link is established with a pair of $25 \mathrm{dBi}$ horn antennas. At the receiver side of the end user section, the received signal is first amplified by a $40 \mathrm{~dB}$ gain low noise amplifier (LNA) and then electrically down-converted to an intermediate frequency (IF) centered at $6.4 \mathrm{GHz}$ using a W-band balanced mixer. The IF signal is then re-modulated onto lightwave at a second MZM and transmitted though a second fiber span of $10 \mathrm{~km}$ SSMF. At the receiver, the IF-over-fiber signal is converted back to electrical domain at a second PD and sampled for offline signal processing and demodulation.

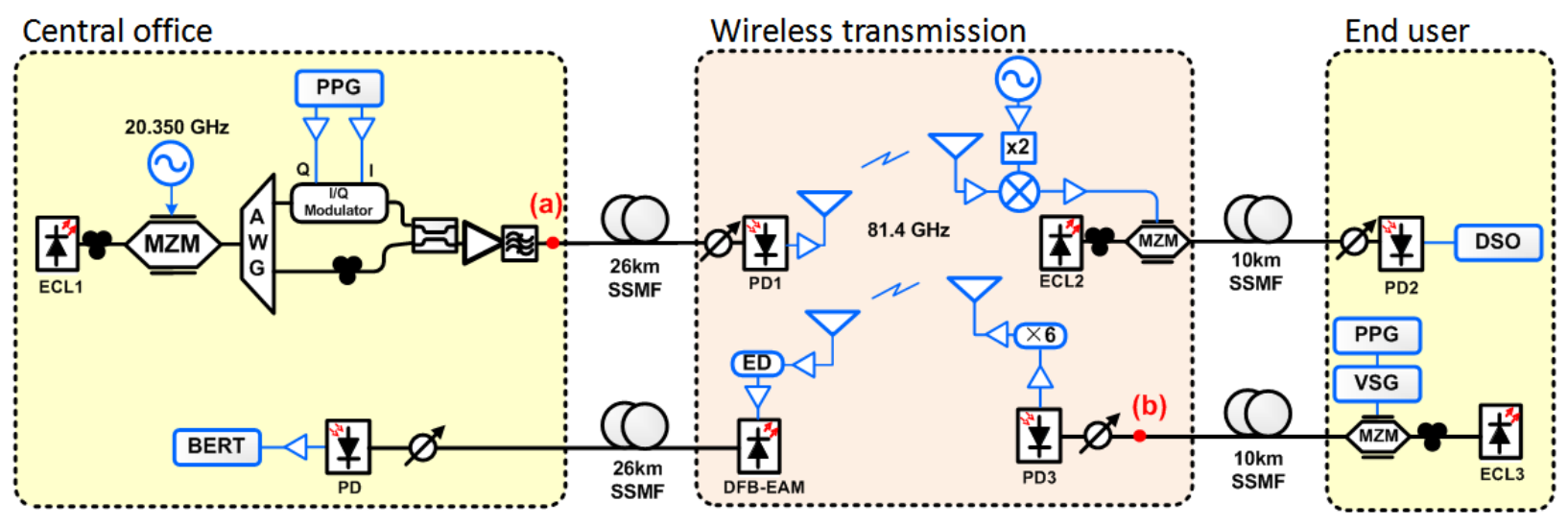

Fig. 2. Experimental setup. ECL: external cavity laser. MZM: Mach-Zehnder modulator. AWG: arrayed waveguide grating. PPG: pulse pattern generator. PD: photodetector. DSO: digital storage scope. VSG: vector signal generator. ED: envelope detector. DFB-EAM: distributed feedback laser - electroabsorption modulator. BERT: bit-error-rate tester.

In the uplink (UL) direction, a $1.25 \mathrm{Gbit} / \mathrm{s}$ electrical signal from a pulse pattern generator (PPG) is first up-converted to an IF at $7.3 \mathrm{GHz}$ by a vector signal generator (VSG). Then the IF signal is modulated at the minimum transmission point of a MZM, forming a carrier suppressed-double sideband (CS-DSB) IF-over-fiber signal, the optical spectrum of which is shown in Fig. 3 (b). The signal is transmitted over the same $10 \mathrm{~km} \mathrm{SSMF}$ as used in the DL before being converted back to electrical at a PD. Then, the IF signal is fed to an electrical frequency sextupler, which up-converts the signal to an $81.6 \mathrm{GHz}$ amplitude shifted-keying (ASK). The signal is then radiated by a 24 $\mathrm{dBi}$ horn antenna. At the wireless receiver, the signal is picked up by an identical antenna and then fed to a zerobiased Schottky diode performing a function of an envelope detector (ED), down-converting the W-band signal directly to baseband. The down-converted signal is directly modulated onto lightwave at a distributed feedback laser - electroabsorption modulator (DFB-EAM). After transmitting the same $26 \mathrm{~km}$ SSMF fiber link as the DL, the signal is recovered by a $10 \mathrm{G}$ PD and the transmission is evaluated in real time by a bit-error-rate tester (BERT).

\section{Results}

Figure 3(a) and 3(b) shows the optical spectra of the downlink and the uplink, respectively. Figure 3(c) shows the BER performance of the downlink transmission with wireless distance of 2, 5 and 10 meters. The curves are presented for a fiber-wireless and a fiber-wireless-fiber link case. As it can be observed, adding the last bit of fiber transmission only adds $0.5 \mathrm{~dB}$ of power penalty. It is noted that longer transmission distances are limited by the frequency selective fading induced by multipath effect in the indoor experimental environment rather than wireless power. Further efforts to mitigate this issue may be necessary, such as multiple input multiple output (MIMO) techniques. 

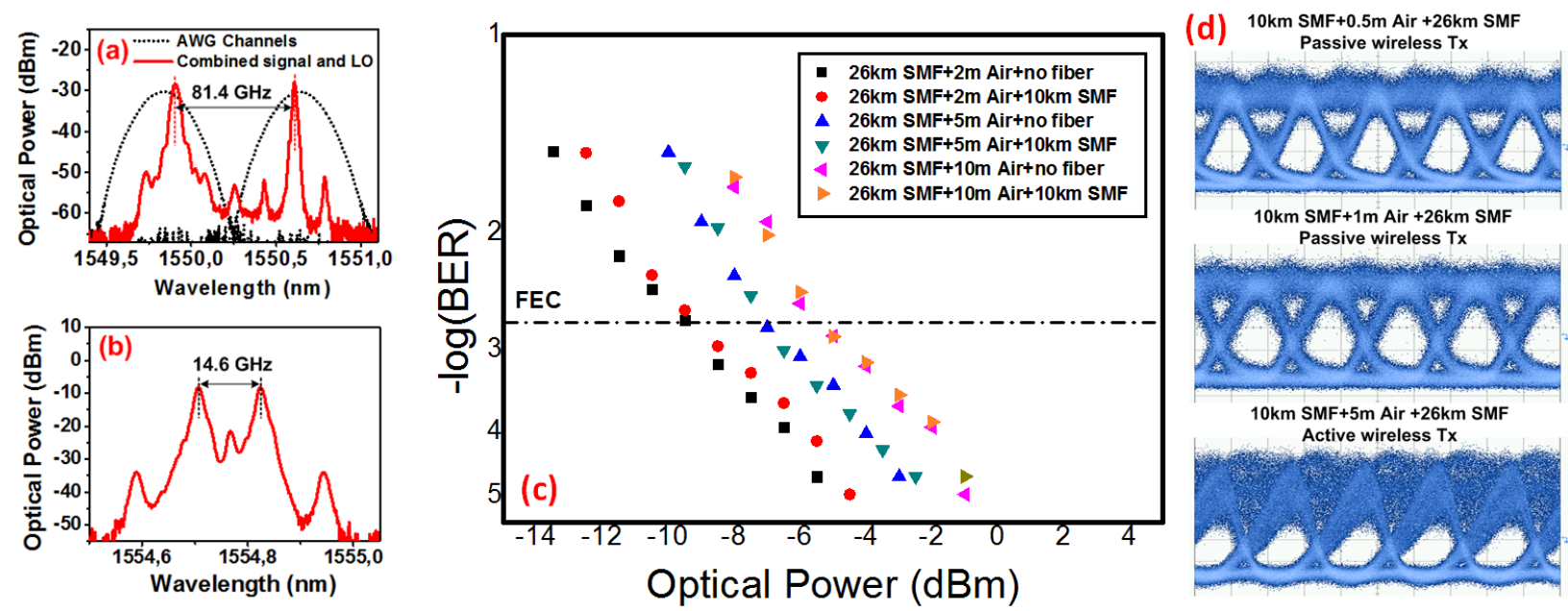

Fig. 3. Optical spectra measured at downlink (a) and the the uplink (b). BER performance of the system for the downlink (c). Eye diagrams of the upstream signal for different wireless transmission lengths (d).

In the UL direction, the wireless transmission is limited to 5 meters due to the physical constrains of the laboratory condition. From Fig. 3(d) we can see that the eye diagrams are clear and open without being distorted when the radiated power is low; however, when amplification is added to increase the wireless length, certain level of distortion in the eye diagram can be observed. In any case, the upstream signal is more immune to frequency selective fading in the indoor environment due to its narrower bandwidth compared with the downlink signal.

\section{Conclusions}

This paper has shown an experimental demonstration of a bidirectional hybrid photonic-wireless link with an 81.4 $\mathrm{GHz}$ W-band wireless transmission and $16 \mathrm{Gbit} / \mathrm{s}$ channel capacity. The intermediate wireless transmission of 10 meters is shown while fiber guided sections compounded a total of $36 \mathrm{~km}$. Both the downlink and the uplink reach error free performance without perceptible error flour, which indicates that the capacity higher bound is yet to be reached. The measurements indicate that this higher bound may be determined by multipath effects in the wireless transmission, rather than fiber transmission. Therefore, this system is suitable for line of sight open spaces as our initial network scenarios.

\section{References}

[1] T. Nagatsuma et al., "Millimeter- and THz-wave Photonics Towards 100-Gbit/s Wireless Transmission," Proc. 23rd Annu. Meeting IEEE Photon. Soc., We4 2010.

[2] J.J. Vegas Olmos et al., "Reconfigurable radio-over-fiber networks: Multiple-access functionality directly over the optical layer," IEEE Trans. Microw. Theory Techn., vol. 58, pp. 3001-3010, 2010.

[3] M. Weiss et al., "27 Gbit/s photonic wireless $60 \mathrm{GHz}$ transmission system using 16-QAM OFDM," Proc. MWP'09, PDP, 2009.

[4] W. Jiang et al., "40 Gb/s RoF Signal Transmission with $10 \mathrm{~m}$ Wireless Distance at $60 \mathrm{GHz}$," in OFC/NFOEC 2012, paper OTu2H.1.

[5] C. Ho et al., "50-Gb/s Radio-over-Fiber System Employing MIMO and OFDM Modulation at $60 \mathrm{GHz}$," in OFC/NFOEC 2012, paper OM2B.3, 2012.

[6] A. Kanno et al., " $40 \mathrm{~Gb} / \mathrm{s}$ W-band (75-110 GHz) 16-QAM radio-over-fiber signal generation and its wireless transmission," Opt. Exp., vol. 19, pp. B56-B63, Dec. 2011.

[7] L. Deng et al., "42.13 Gbit/s 16qam-OFDM photonics-wireless transmission in 75-110 GHz band," Progress In Electromagnetics Research, vol. 126, pp. 449-461, 2012.

[8] X. Pang et al., "100 Gbit/s hybrid optical fiber-wireless link in the W-band (75-110 GHz)," Opt. Exp., vol. 19, pp. 24944-24949, Dec. 2011.

[9] J. Zhang et al., "Multichannel 120-Gb/s Data Transmission Over 2 x 2 MIMO Fiber-Wireless Link at W-Band," IEEE Photon. Technol. Lett., vol.25, no.8, pp.780,783, 2013

[10] S. Koenig et al., "100 Gbit/s Wireless Link with mm-Wave Photonics," in OFC/NFOEC 2013, paper PDP5B.4, 2013.

[11]H. Kiuchi et al., "High Extinction Ratio Mach-Zehnder Modulator Applied to a Highly Stable Optical Signal Generator," IEEE Trans. Microw. Theory Techn., vol.55, pp.1964, 2007.

[12]X. Pang et al., "Experimental characterization of a hybrid fiber-wireless transmission link in the 75 to $110 \mathrm{GHz}$ band," Opt. Eng., vol. 51, pp. 045004-1-045004-5, 2012.

\section{Acknowledgements}

J.J. Vegas Olmos acknowledges the Marie Curie program for partly funding this research through the WISCON project. 